\title{
ORIGEM SOCIAL E RACIAL E A FORMAÇÃO DE ENFERMEIRAS PROFISSIONAIS NO BRASIL (1930-1960) ${ }^{1}$
}

Luiz Otávio Ferreira ${ }^{2}$

Nara Azevedo

Resumo: O artigo retoma a discussão sobre a configuração da profissão de enfermagem na sociedade brasileira focalizando os mecanismos institucionais que imprimiram à profissão uma composição social e racial característica. Especificamente, pretende analisar os efeitos da adoção de mecanismos institucionais de seleção baseados na origem social, no gênero, no tipo de escolaridade e na raça sobre a composição social da profissão. Um dos efeitos da adoção de políticas excludentes de seleção de candidatos para o ingresso nas escolas de enfermagem foi a produção de um déficit crônico de profissionais. A definição prévia de um perfil social e racial desejado para a enfermeira tornou o projeto de constituição da profissão virtualmente irrealizável, sobretudo quando o papel social proposto para as profissionais seria o de atuar como protagonistas no sistema de saúde pública e de assistência hospitalar em implantação no país.

Palavras-chave: Enfermagem; Classe Social; Gênero; Raça; Mobilidade Social

\section{SOCIAL AND RACIAL ORIGIN AND THE FORMATION OF PROFESSIONAL NURSES IN BRAZIL (1930-1960)}

\begin{abstract}
The article resumes the discussion about the configuration of the nursing profession in Brazilian society focusing on the institutional mechanisms that have given the profession a characteristic social and racial composition. Specifically, it intends to analyze the effects of the adoption of institutional mechanisms of selection based on social origin, gender, type of schooling and race on the social composition of the profession. One of the effects of the adoption of exclusionary policies to select candidates for admission to nursing schools was the production of a chronic shortage of professionals. The prior definition of a desired social and racial profile for the nurse made the professionalization project virtually unfeasible, especially when the social role proposed for the professionals would be to act as protagonists in the public health system and hospital care in implantation in the parents.
\end{abstract}

Key-words: Nursing; Social Class; Gender; Race; Social Mobility.

\section{ORIGINE SOCIALE ET RACIALE ET FORMATION D'INFIRMIÈRES PROFESSIONNELLES AU BRÉSIL (1930-1960)}

Resumé: L'article reprend la discussion sur la configuration de la profession d'infirmière dans la société brésilienne, en mettant l'accent sur les mécanismes institutionnels qui ont donné à la profession une composition sociale et raciale caractéristique. Plus précisément, nous avons l'intention d'analyser les effets de l'adoption de mécanismes institutionnels de sélection fondés sur l'origine sociale, le sexe, le type de scolarité et la race dans la composition sociale de la profession. L'adoption de politiques d'exclusion visant à sélectionner les candidats à l'admission

\footnotetext{
${ }^{1}$ A pesquisa que resultou no artigo foi desenvolvida sob os auspícios do Edital Negros e Negras nas Ciências, lançado em 2016 pela Fundação Carlos Chagas (FCC) e Ford Foundation.

${ }^{2}$ Faculdade de Educação da Universidade Estadual do Rio de Janeiro (UERJ), Rio de Janeiro (RJ), Brasil. E-mail: luiz.ferreira@ fiocruz.br

${ }^{3}$ Casa de Oswaldo Cruz (Fiocruz), Rio de Janeiro (RJ), Brasil; nara.azevedo@fiocruz.br
} 
dans les écoles de sciences infirmières a eu pour effet de produire une pénurie chronique de professionnels. La définition préalable d'un profil social et racial souhaité pour l'infirmière rendait le projet de professionnalisation pratiquement irréalisable, surtout lorsque le rôle social proposé par les professionnels jouerait le rôle de protagoniste du système de santé publique et hospitalier dans l'implantation chez les parents.

Mots-clés: Soins Infirmiers; Classe Sociale; Genre; Race; Mobilité Sociale.

\section{ORIGEN SOCIAL Y RACIAL Y LA FORMACIÓN DE ENFERMERAS PROFESIONALES EN BRASIL (1930-1960)}

Resumen: El artículo retoma la discusión sobre la configuración de la profesión de enfermería en la sociedad brasileña, enfocando los mecanismos institucionales que dieron a la profesión una composición social y racial característica. En concreto, se pretende analizar los efectos de la adopción de mecanismos institucionales de selección basados en el origen social, género, tipo de escolaridad y raza en la composición social de la profesión. Uno de los efectos de la adopción de políticas excluyentes para seleccionar candidatos para admisión en escuelas de enfermería fue la producción de una escasez crónica de profesionales. La definición previa de un perfil social y racial deseado para el enfermero hizo el proyecto de profesionalización prácticamente inviable, especialmente cuando el papel social propuesto por los profesionales sería actuar como protagonista en el sistema público de salud y hospitalario en la implantación en los padres.

Palabras-clave: Enfermería; Clase Social; Género; Raza; Movilidad Social.

Não são muitos os estudos que, tratando do processo histórico de formação da enfermagem moderna no Brasil, dão ênfase à questão da composição social e racial desse grupo profissional. Embora se observe a publicação de "estudos de perfil" sobre a condição sociocultural e econômica da população estudantil de determinadas escolas ou faculdades de enfermagem, apenas recentemente se empreendeu um estudo de larga escala sobre o perfil sociodemográfico dos profissionais em atuação no país (Machado et al., 2015). Os resultados obtidos apontam que atualmente a corporação da enfermagem portadora de diploma de nível superior e de ensino técnico é formada por 414.172 profissionais. O estudo citado revela que a enfermagem é uma profissão feminina (85\%), relativamente jovem (25 a 40 anos) e de cor branca (58\%).

Neste artigo pretendemos retomar a discussão sobre a configuração da profissão de enfermagem na sociedade brasileira, focalizando os mecanismos institucionais que imprimiram à profissão uma composição social característica. Especificamente, pretendemos analisar os efeitos da adoção de mecanismos institucionais de seleção baseados na origem social, no gênero, no tipo de escolaridade e na raça sobre a composição social da profissão. Um dos efeitos da adoção de políticas excludentes de seleção de candidatos para o ingresso nas escolas de enfermagem foi a produção de um 
déficit crônico de profissionais. A definição prévia de um perfil social e racial para a enfermeira tornou o projeto de constituição da profissão virtualmente irrealizável, sobretudo quando o papel social proposto para as profissionais seria o de atuar como protagonistas no sistema de saúde pública e de assistência hospitalar em implantação no país.

Nosso argumento é que, a despeito de ter sido projetada para ser uma profissão da elite, a enfermagem se viabilizou justamente porque, contrariando as expectativas iniciais, se tornou uma profissão mais aberta à presença de outros grupos sociais que aproveitaram, mesmo que com muitas restrições, das oportunidades de mobilidade social propiciadas por políticas públicas modernizadoras no campo da saúde e da educação. A pergunta que pretendemos responder é: a enfermagem profissional ofereceu oportunidades de mobilidade social para mulheres negras oriundas das classes pobres urbanas?

\section{A ENFERMAGEM MODERNA}

A formação de enfermeiras profissionais foi um dos principais objetivos da política de saúde implantada no Brasil a partir da década de 1920. Para os médicos que dirigiam as agências estatais responsáveis pela gestão da saúde pública, a transformação da situação sanitária do país e a decorrente melhoria das condições de saúde da população dependeriam do surgimento de uma legião de enfermeiras profissionais. A criação de uma rede nacional de escolas de enfermagem foi assumida como um empreendimento estratégico que exigiu esforços político-institucionais e culturais complexos: firmar acordos pedagógicos e científicos com agências privadas e estatais norte-americanas; negociar com a Igreja Católica o lugar que a caridade deveria ocupar na prestação da assistência à saúde, e empreender a modernização do papel social de gênero de um grupo específico de mulheres pertencentes às classes médias urbanas.

Um dos primeiros estudos sociológicos sobre a constituição de enfermagem como profissão no Brasil oferece uma perspectiva interessante para a discussão sobre os significados atribuídos à enfermagem moderna:

Cuidar dos doentes, preparar os mortos, assistir as mulheres na hora do parto, dar conforto aos que sofrem, são funções que tradicionalmente pertençam às mulheres [...] Muitos desses cuidados foram institucionalizados no mundo 
moderno e ocupações novas substituíram o improvisar por bom senso e "intuições femininas". Agentes funerários, companhias de seguro, organizações de assistência social, obstétricos, pedagogos e enfermeiros diplomados substituíram com perícia e técnica os cuidados ministrados por mulheres, cuidados que estas aprendiam informalmente através de elementos das gerações mais velhas do mesmo sexo. (Ferreira-Santos, 1973, p. 3)

Antes de tudo, é preciso notar que a enfermagem moderna não se estabeleceu numa linha de continuidade com as práticas de assistência e de cuidado tradicionalmente exercidas por mulheres no âmbito do espaço doméstico. Pelo contrário, as enfermeiras profissionais desejavam e se esforçaram para serem reconhecidas como antípodas, como representantes do mundo moderno dominado pela ciência e pela técnica, em face aos valores e práticas tradicionais. A enfermeira moderna não deveria ser confundida sob nenhum aspecto com mulheres que exerciam as artes de curar e de cuidados tradicionais.

Nesse sentido, a identidade de gênero frequentemente citada como um traço comum entre a enfermagem moderna e as práticas tradicionais de assistência constitui, na verdade, o ponto de afastamento a partir do qual se deu a construção da distinção social da enfermeira profissional. Para diferenciar as enfermeiras dos tradicionais grupos de mulheres praticantes das artes populares de cura - das cuidadoras domésticas e até mesmo das enfermeiras "empíricas" que atuavam em hospitais -, tornou-se imperativo que as futuras profissionais fossem escolhidas entre mulheres oriundas das classes mais ricas e escolarizadas da sociedade. Nesse sentido, a legitimidade cultural da enfermagem moderna dependeria da origem social das mulheres a serem profissionalizadas.

A enfermagem profissional moderna, de acordo com a historiadora Michelle Perrot (2005), está relacionado à institucionalização do trabalho social ocorrido na Europa na transição do século XIX para do século XX. As protagonistas desse processo formaram associações femininas dedicadas à caridade e à filantropia, comandadas por mulheres de classe média. A caridade e a filantropia - "gestão privada do social" - dirigida para a pobreza urbana foi o espaço público ocupado e transformado pelas associações femininas. O trabalho voluntário desenvolvido em hospitais, creches, asilos, dispensários, etc. proporcionou às filantropas burguesas "uma experiência não negligenciável que modificou sua percepção do mundo, seu sentido de si mesma e, até certo ponto, sua inserção pública" (PERROT, 2005, p. 281). Se primeiramente tratava-se de "fazer caridade" no sentido convencional, o envolvimento cada vez mais profundo com os 
problemas relacionados à "questão social" transformou o trabalho voluntário e benemérito numa "cruzada de moralização e de higiene" (Perrot, 2005, p. 282). O trabalho social foi um campo fértil para o amadurecimento de saberes e técnicas que credenciaram as mulheres burguesas para o exercício de funções públicas com autoridade reconhecida, e que abriu as portas para a profissionalização. As bases das profissões femininas ensinar, cuidar, assistir - não resultaram, portanto, da adaptação passiva de tarefas tradicionais atribuídas às mulheres, mas sim da institucionalização de experiências específicas e localizadas de mulheres burguesas no campo do trabalho social.

A historiografia que estuda os processos de institucionalização de enfermagem profissional em países latino-americanos (Vessuri, 2001; Clark, 2012; Biernat, Cerdá; Ramacciotti, 2015) observa um problema comum presente em diferentes contextos nacionais: o recrutamento de estudantes. Aparentemente, não houve sintonia entre a oferta pública e privada de vagas para os cursos de enfermagem e a adesão voluntária de mulheres atraídas pela nova oportunidade de profissionalização. O número insuficiente de enfermeiras diplomadas tornou-se um problema crônico.

Analisando a instauração da enfermagem profissional na Venezuela ocorrida durante a década de 1940, a socióloga Hebe Vessuri (2001) discute como a educação e a classe social se tornaram os "temas críticos" e as "variáveis significativas" que imperaram durante o difícil processo de institucionalização. Na Venezuela, assim como em muitos países latino-americanos, a formação de enfermeiras profissionais foi caracterizada pela intervenção da Fundação Rockefeller. ${ }^{4}$ Seguindo um procedimento padrão, ela mobilizou recursos financeiros e humanos com o propósito de criar escolas de nível superior para a formação de enfermeiras profissionais capacitadas para atuar no campo da saúde pública e da assistência hospitalar. De acordo com os preceitos político-ideológicos que fundamentavam sua ação institucional, Fundação Rockefeller propunha que a missão social das enfermeiras profissionais seria a de disseminar entre as populações pobres os valores e hábitos sanitários, e educar técnica e moralmente outras enfermeiras para cumprirem as mesmas obrigações. Nesse sentido, a triagem das candidatas para o ingresso

\footnotetext{
${ }^{4}$ Entidade de filantropia norte-americana que se dedicava ao patrocínio da pesquisa biomédica e da formação de profissionais de saúde, atuando mediante acordos de cooperação estabelecidos com os governos locais. Sobre a atuação da Fundação Rockefeller no Brasil e América Latina consultar trabalho de Marcos Cueto (1994) e Maria Gabriela Marinho (2001).
} 
na escola de enfermagem deveria ser feita segundo critérios bastante seletivos: exigia-se que as estudantes fossem mulheres jovens oriundas das elites locais e com educação secundária.

No caso venezuelano o peso de uma cultura tradicional fez com que poucas jovens educadas de "boas famílias" manifestassem interesse e tivessem o apoio familiar para adotarem a profissionalização como um projeto de vida. Na prática, a maioria das estudantes não procedia da elite ou da classe média, e nem possuía a escolaridade secundária completa. A consequência disso foi que a "pobreza da base cultural e educativa da maioria das candidatas" (Vessuri, 2001, p. 521-522) converteu-se na explicação oficial não apenas para a escassez de "boas enfermeiras", mas, sobretudo, para o fracasso da tentativa de consolidar a enfermagem como uma profissão de elite capaz de exercer papéis de liderança institucional e intelectual.

No Brasil, entre 1890 e 1950, registra-se o funcionamento de cerca de 26 escolas de enfermagem profissionais. A maioria - 13 escolas - era de orientação religiosa com predomínio da Igreja Católica. As escolas públicas, de âmbito federal ou estadual, somavam 11 instituições. Somente duas escolas de enfermagem funcionavam como entidades filantrópicas. Apesar da distribuição por todas as regiões do país, a maioria das escolas - 15 - estava concentrada na região Sudeste, especificamente nos estados do Rio de Janeiro, São Paulo, Minas Gerais e no Distrito Federal. Apesar disso, entre 1917 e 1942, diplomaram-se apenas 3.131 enfermeiras (Ribeiro, 1954, p. 11). Em 1963, o número de enfermeiras diplomadas havia dobrado, aumentando para 7.310 profissionais (Resende, 1967, p. 166).

Na década de 1920, o ensino de enfermagem brasileiro adotou o modelo norteamericano, que foi implantado mediante um acordo de cooperação assinado entre o governo federal, especificamente o Departamento Nacional de Saúde Pública (DNSP), e a Fundação Rockefeller. A princípio a tarefa da missão das enfermeiras norte-americanas era promover o (re)treinamento das "enfermeiras visitadoras" que já atuavam nos serviços de tuberculose e de higiene infantil do DNSP na capital federal. Em seguida, deu-se início à formação de enfermeiras profissionais propriamente ditas, com a fundação de uma escola de enfermagem padrão na capital federal - a Escola de Enfermeiras Anna Nery. As enfermeiras norte-americanas permaneceram à frente da Escola Anna Nery por 10 
anos, entre 1923 e 1933. Até o final da década de 1940, a principal missão da Escola Anna Nery foi a de servir de modelo pedagógico e institucional - "escola padrão" - para as demais escolas de enfermagem do país, e, mais importante, formar enfermeiras profissionais capazes de se responsabilizarem pela formação de outras enfermeiras profissionais.

Na primeira fase de institucionalização de enfermagem profissional no Brasil, o mais importante não era a quantidade, mas sim a "qualidade" social e cultural das enfermeiras. Por isso, foi dada especial atenção à formação de uma elite profissional constituída por enfermeiras brasileiras treinadas no exterior (Estados Unidos e Canadá) com o apoio do programa de bolsa patrocinado pela Fundação Rockefeller.

Chamando atenção para as diferenças entre o modelo norte-americano e o modelo inglês de enfermagem, Luiz Antônio de Castro-Santos e Lina Faria (2009) observam que tais diferenças teriam impacto e gerariam tensões já que o ambiente social aqui encontrado pela missão de enfermeiras norte-americanas

[a sociedade brasileira] seria um ambiente muito mais consentâneo com a 'tradição inglesa': ênfase na legislação de cunho federal, uniformizadora, e a predominância, numa sociedade hierárquica como a brasileira, de critérios discriminadores e não democráticos para a seleção das primeiras turmas de enfermeiras que comporiam a elite profissional. (Castro-Santos; Faria, 2009, p. 84)

A adaptação do modelo pedagógico e da ideologia da enfermagem norteamericana exigiu um ajuste em função dos valores culturais e hierarquias sociais locais referentes a classe social, gênero e raça.

O modelo norte-americano de formação de enfermeiras preconizava uma rígida orientação pedagógica que impunha critérios acadêmicos até então inéditos no sistema educacional brasileiro: dedicação integral das docentes, definição de padrões técnicos de trabalho de enfermagem hospitalar e de saúde pública, e um enfoque operacional para a organização das campanhas sanitárias. A formação proporcionada pelas escolas de enfermagem respaldava-se na convicção de que a enfermagem consistia em uma profissão de base técnico-científica.

Além do rigor acadêmico, a socialização da enfermeira profissional exigia a adesão a determinados valores, regras, hierarquias e símbolos que foram fortemente 
associados à profisssão: nacionalismo, abnegação religiosa e feminilidade. As escolas de enfermeiras funcionavam em regime de internato, e as alunas eram submetidas a um rigoroso controle. A exigência de desempenho escolar exemplar e a extenuante carga horária de estágio nos hospitais ou em postos de saúde seriam recompensadas no futuro com a distinção social conferida pelo diploma de nível superior e com boas oportunidades profissionais.

As escolas de enfermagem funcionavam em regime de internato, o que implicava algum tipo de financiamento público ou privado. Uma escola deveria estar equipada de dormitórios, refeitórios, salas de aulas, espaços para a realização de atividades esportivas, ambientes de lazer, lavanderia, biblioteca, enfermaria e até mesmo uma pequena capela para a realização de cerimônias religiosas. Não eram cobradas mensalidades e praticamente todas as alunas eram subvencionadas com recursos públicos ou com bolsas de estudo fornecidas por entidades privadas. O regime de internato foi utilizado pela propaganda institucional das escolas de enfermagem como um recurso para atrair candidatas e também para oferecer às famílias a garantia de que suas filhas estariam estudando em ambiente moralmente seguro.

\section{CHAMEM AS NORMALISTAS}

Os métodos de recrutamentos utilizados para atrair potenciais alunas não escondiam a preferência por um determinado perfil sociocultural: mulheres jovens e solteiras, de cor branca, oriundas das elites ou das classes médias urbanas e com escolaridade secundária. $\mathrm{O}$ grupo social que mais se aproximava do tipo idealizado era o das normalistas e, por isso, as professoras primárias foram fortemente incentivadas a aderir à nova profissão sanitária.

De modo geral, foi muito baixa a adesão de mulheres que atendiam plenamente os requisitos estabelecidos. Pelo menos três fatores culturais contribuíram para esse resultado: a) a escolaridade secundária requerida não era comum nem mesmo entre as mulheres oriundas das elites e das classes médias urbanas; b) o rigoroso processo de socialização era incomum mesmo nas escolas normais; c) o preconceito a respeito do status social da enfermagem, cujas práticas eram culturalmente associadas a uma forma de trabalho manual. 
O relatório do processo de seleção de candidatas para a turma de 1929 da Escola Anna Nery expõe os detalhes do ritual de recrutamento (Escola Anna Nery, 1929). Diante de uma comissão composta por um médico brasileiro, duas enfermeiras norte-americanas e uma enfermeira brasileira se apresentaram 24 candidatas. As cinco candidatas que apresentaram o diploma do curso normal foram imediatamente encaminhadas ao exame médico, ficando dispensadas do exame escrito de conhecimentos. As 16 candidatas que tinham "estudos incompletos" foram submetidas ao exame escrito. Três candidatas foram eliminadas por "falta de instrução". Já iniciado o processo seletivo, se apresentaram mais duas candidatas - uma delas, normalista e outra, "em condições de fazer os exames" que justificaram o atraso alegando problemas com os correios. Das 17 candidatas submetidas ao exame escrito, 11 obtiveram aprovação plena, quatro foram aprovadas "sob condição" e duas reprovadas. Mas, depois de encerrado o processo de exames físico e escrito, duas candidatas (uma delas normalista) foram eliminadas. Assim, a turma de 1930 da Escola Anna Nery foi composta por 19 alunas.

O caso chama a atenção pelo uso de mutáveis critérios por parte da comissão que iam desde a aprovação quase automática de candidatas normalistas até a exclusão de candidatas bem-sucedidas em todas as fases do processo seletivo com base em meras suspeitas.

A composição social e racial das primeiras turmas de estudantes da Escola Anna Nery que ingressaram nas décadas de 1920 e 1930 foi estudada por Simone dos Santos Menezes, Suely de Souza Baptista e Ieda de Alencar Barreira (1998). Elas constataram o predomínio de um tipo social bem específico: mulheres jovens (20 anos de idade em média), solteiras, provenientes das classes médias urbanas e portadoras de diploma de normalista. Outro aspecto relacionado à dinâmica do processo de socialização das primeiras turmas da Escola Anna Nery foi analisado por Lorena Raeli Ligeiro e Suely de Souza Baptista (1999). O estudo verificou que 158 das 376 alunas matriculadas entre 1930 e 1938 formam excluídas por motivos variados, como desempenho escolar insatisfatório, inadaptação ao regime de internato ou indisciplina. A exclusão de $42 \%$ das alunas indica que os mecanismos seletivos permaneciam ativos mesmo depois de superada a fase de admissão. 
A historiografia (CAMPOS, 2012, 2008) aponta que os objetivos da formação de enfermeiras no país foram alterados a partir de 1942, quando o governo de Getúlio Vargas, no contexto da participação brasileira na $2^{\mathrm{a}}$ Guerra Mundial e amparado em acordos de cooperação internacional com o Instituto de Assuntos Interamericanos (IIAA), órgão do Departamento de Estado norte-americano, criou o Serviço Especial de Saúde Pública (SESP). Os anos de 1940 a 1950 foram marcados pelos esforços do SESP e do Departamento Nacional de Saúde, com apoio da Oficina Sanitária Pan-Americana e da Fundação Rockefeller, para "corrigir os rumos" do processo de institucionalização da enfermagem no Brasil que, após 20 anos de andamento, ainda não apresentava resultados capazes de atender às demandas de assistência hospitalar nos centros urbanos e de saúde pública em determinadas regiões rurais do país.

Um dos problemas que deveria ser enfrentado era o da escassez de enfermeiras diplomadas. A solução não era simples. Ao mesmo tempo em que foram criadas novas escolas de enfermagem, com destaque para a Escola de Enfermagem da Universidade de São Paulo (EEUSP), instituída em 1942, também se discutia a regulamentação da obrigatoriedade do diploma de ensino secundário para o ingresso nas escolas de enfermagem. Embora, desde a década de 1920, a recomendação oficial fosse para que todas as alunas tivessem escolaridade secundária, medida que garantiria a homogeneidade sociocultural do corpo estudantil, na prática, apenas as normalistas preenchiam o requisito.

A reforma do ensino de enfermagem ocorreu paralelamente a uma grande reformulação da educação no país - a chamada reforma Capanema (1942)-, que alterou profundamente a estrutura do ensino superior e do ensino secundário. Nesse contexto, as escolas de enfermeiras deveriam ser incorporadas ao sistema de ensino superior, constituído por universidades e por faculdades isoladas. Se a incorporação universitária das escolas de enfermeiras teria significado simbólico favorável para reconhecimento social da profissão, por outro lado, agravaria o problema da escassez de enfermeiras, já que a premissa básica para o ingresso no ensino superior era a posse do diploma de nível secundário. Pressionadas, as escolas de enfermeiras, junto com os dirigentes estatais da saúde, encontraram uma solução conciliatória: somente as escolas incorporadas às universidades estariam obrigadas a cumprir a exigência do diploma de ensino secundário. 
As escolas de enfermeiras isoladas poderiam continuar aceitando alunas com menor nível de escolaridade. A solução conciliatória permaneceu válida até a promulgação da primeira Lei de Diretrizes e Bases da Educação, em 1961. A formação de enfermeiras profissionais estava submetida a uma dialética contraditória.

Como vimos discutindo até aqui, os requisitos de classe social, escolaridade e raça, tidos como absolutamente necessários para a legitimação social da profissão de enfermeira, na prática funcionaram com um poderoso entrave para a expansão efetiva desse grupo profissional. Apesar de ostensivamente convocadas, as normalistas brancas de classe média não se apresentaram em número considerado suficiente. A pressão exercida pelas demandas crescentes por assistência à saúde oriundas de setores como servidores públicos e trabalhadores urbanos "com carteira assinada" inscritos no sistema previdenciário obrigou a abertura da profissão a outros grupos de mulheres e até mesmo para os homens.

\section{ENFERMEIRAS NEGRAS}

O acesso de candidatas negras à Escola Anna Nery na década de 1930 foi estudado por Márcia Cristina Lucas Ferreira, Antônia Regina Messias Fernandes Sena e Ieda de Alencar Barreira (1999). Segundo as autoras, a exclusão sistemática de moças negras e mestiças foi uma diretriz institucional que estava em conformidade com o estereótipo social que se pretendia construir para a enfermeira profissional brasileira. Tentava-se evitar que mulheres negras se candidatassem a uma vaga na instituição. Mas nem sempre isso era possível.

Um episódio emblemático de discriminação racial ocorrido nos primeiros anos de funcionamento da Escola Anna Nery é frequentemente citado pela historiografia (Souza Campos, 2008 Souza Campos, Paulo Fernando de; Oguisso, Taka, p. 895; Moreira, 1999,

p. 11). Em 1926, jornais "oposicionistas" denunciaram que todas as "moças de cor" que se apresentavam como candidatas a uma vaga eram rejeitadas, mesmo que fossem física e culturalmente aptas. Para desmentir a denúncia, os dirigentes do Departamento Nacional de Saúde Pública, órgão responsável pela Escola Anna Nery, teriam permitido a aprovação de uma candidata negra. No entanto, houve uma forte reação das alunas 
brancas, que aceitaram a presença da estudante negra sob a condição de que outras iguais a ela não seriam admitidas.

Mesmo assim, de acordo com Ferreira, Sena e Barreira (1999), os documentos e os registros fotográficos consultados por elas indicariam a presença de alunas negras posteriormente ao evento acima descrito.

A presença de alunas negras também foi observada por Renata Batista Brotto (2012) na Escola de Enfermeiras Luiza de Marilac, de orientação católica vinculada à Congregação das Filhas de Caridade e à Associação São Vicente de Paulo, criada no Rio de Janeiro, capital federal, em 1938. Como ocorria na Escola Anna Nery, a candidatura de mulheres negras também foi desestimulada. Mesmo assim, entre 1943 e 1961, registrou-se a matrícula de 19 alunas que se declararam preta, parda, morena ou mulata, número que perfazia 4,6\% do total de 408 alunas cuja documentação foi analisada. Um dado que é importante observar é que a Escola Luiza de Marilac recrutava alunas em todas as regiões do país e, apesar de estar localizada na cidade do Rio de Janeiro, mais da metade das alunas eram naturais da região Nordeste.

O historiador Paulo Fernando Souza Campos (2008, 2013) defende que a Escola de Enfermagem da USP foi precursora ao adotar uma política de recrutamento menos restritiva, aceitando em seu quadro estudantes mulheres negras e também homens. Embora não apresente uma demografia extensa sobre a composição social e racial do corpo estudantil, o autor descreve o perfil de algumas poucas alunas negras, incluindo no grupo as que se declararam pardas, mulatas ou morenas. Tratava-se de moças detentoras do diploma do curso normal (ensino secundário), de origem social modesta e já “inseridas no universo do cuidado, atuando como professoras, visitadoras sanitárias, samaritanas, socorristas e auxiliares de médicos" (Souza Campos, 2008, p. 897). Também são destacadas as carreiras profissionais bem-sucedidas, o que confirmaria, na opinião do autor, um sinal da "reconfiguração da identidade profissional" (p. 897 da enfermeira até então fortemente associada a um tipo social e racial bem determinado.

Por outro lado, ainda no universo da enfermagem paulista, o estudo empreendido por Célia Almeida Ferreira-Santos (1973) sobre a atuação de enfermeiras diplomadas em um hospital-escola universitário indicou que não havia nenhuma mulher negra entre as 
12 enfermeiras-docentes e nem entre as 25 enfermeiras que atuavam nas equipes médicas do hospital. Acreditamos que a ausência de enfermeiras negras no hospital-escola pode ser entendida quando se observa o perfil socioeconômico do grupo de enfermeiras atuantes naquela instituição, constituído de mulheres oriundas de um setor específico da classe média (trabalhadores não manuais na definição da época) no qual os pais não detinham o mesmo nível de escolaridade superior já alcançado pelas filhas. As enfermeiras negras geralmente não provinham de famílias desse tipo de classe média, mas sim das classes trabalhadoras mais pobres do ponto de vista material e cultural. Combinando os cenários apresentados por Souza Campos e Ferreira-Santos, podemos sustentar que, no estado de São Paulo nos anos 1950 e 1960, a enfermagem se apresentava como uma profissão que oferecia oportunidades de mobilidade social para diferentes grupos de mulheres, inclusive as mulheres negras.

Mas qual foi a percepção institucional das escolas de enfermeiras a respeito das mudanças que vinham ocorrendo na composição social do corpo estudantil?

Um sugestivo estudo realizado no início dos anos 1970 pela enfermeira Djair Daniel Nakamae (1975) com 150 estudantes das seis escolas de enfermagem existentes no estado de São Paulo mostra como as transformações na composição social do corpo estudantil estavam sendo percebidas. Os resultados destacados pela autora mostram a predominância quase absoluta de mulheres oriundas das classes médias baixas, a presença expressiva de estudantes descendentes de japoneses, a alta incidência de normalistas e a importante participação de estudantes que trabalhavam antes e depois do ingresso nas escolas de enfermeiras, o que era mais um indicativo da origem social modesta.

Comentando os resultados a partir da perspectiva das "enfermeiras educadoras", Nakamae considerou que as escolas de enfermeiras estavam "diante de um panorama não muito otimista", já que grande parte das estudantes não tinha a "preparação adequada ao currículo das escolas de enfermagem" e necessitava trabalhar em vez de se dedicar integralmente aos estudos (1975, p. 347). Chama atenção nos comentários a respeito do perfil socioeconômico das estudantes paulistas a reversão de expectativa quanto à importância atribuída à presença de normalistas na composição social do corpo estudantil. Enquanto, até a década de 1960, as normalistas representavam o tipo ideal da estudante de enfermagem, no início da década de 1970, a "alta incidência de normalistas" (p 
347)passou a ser vista como um sério problema. Agora o ideal seriam estudantes (mulheres e homens) que "procedessem do curso científico", modalidade do curso secundário que ofereceria uma formação escolar mais adequada ao currículo dos cursos de enfermagem.

Outra mudança que ajuda a compreender melhor quem eram as "novas" estudantes de enfermagem em São Paulo foi a extinção do regime de internato ocorrida junto com a reforma universitária de 1968. Como observa corretamente Nakamae, a oferta de alojamento gratuito atraía "grande número de estudantes", especialmente aquelas que vinham de cidades do interior ou de outros Estados e que não poderiam estudar sem esse apoio institucional (1975 p. 358).

A proximidade social entre as enfermeiras profissionais e as professoras primárias que, aos olhos das "enfermeiras educadoras", se apresentava como um problema foi observado também por Maria Cristina Bruschini (1978, p. 11). Embora a proximidade social entre enfermeiras e professoras preocupasse, quando colocadas numa escala de níveis de escolaridade familiar e, portanto, de status social, as enfermeiras vinham abaixo do nível das professoras, que, por sua vez, se posicionavam abaixo do nível das engenheiras. O prestígio social da profissão de enfermagem estava determinado pela origem social das estudantes.

A origem social das professoras se assemelha à das enfermeiras, pois elas provêm, em grande parte, das classes média baixa e média alta. No entanto, no que diz respeito à instrução dos pais, elas se situam numa posição superior à daquele outro grupo profissional: $28 \%$ dos pais das professoras atingiram nível de escolaridade acima do $2^{\circ}$ ciclo, enquanto $36 \%$ de suas mães seguiram seus estudos até depois do ginásio, em comparação a $14,3 \%$ e $18,4 \%$, respectivamente, entre os pais das enfermeiras. O nível de escolaridade dos pais das professoras não chega, no entanto, a ser tão elevado quando o dos pais das engenheiras. (Bruschini 1978 ano, p 11)

A partir de agora, podemos discutir os resultados de um estudo sobre origem social de dois grupos de estudantes negras que frequentaram com sucesso duas escolas públicas de enfermagem em funcionamento entre as décadas de 1930 e 1960. As escolhidas foram a Escola de Enfermeiras Carlos Chagas (EECC) e a Escola de Enfermeiras Rachel Haddock Lobo (EERHL). 
Criada em 1933 pelo governo do estado de Minas Gerais, a Escola de Enfermeiras Carlos Chagas tinha como finalidade atender às necessidades locais de saúde pública e de assistência hospitalar. É conveniente lembrar que Belo Horizonte, cidade que sediava a escola, era um projeto urbanístico recente, uma cidade planejada e "higiênica", inaugurada no início de século XX para ser a nova capital moderna do estado de Minas Gerais. A EECC foi a primeira escola de enfermagem estadual criada segundo os moldes da Escola de Enfermeiras Anna Nery (EEAN). Trata-se, portanto, de uma escola de enfermagem que deveria seguir o modelo pedagógico norte-americano de formação de enfermeiras com forte ênfase na atuação em serviços de saúde pública. No entanto, a forte influência exercida pela Igreja Católica mineira na gestão da EECC fez com que a assistência hospitalar e o serviço em obras pias de caridade dominassem o repertório de formação das estudantes de enfermagem. Em 1950, a EECC foi incorporada à Universidade de Minas Gerias (atual UFMG), o que, supostamente, trouxe implicações sobre a forma de recrutamento de alunas, especialmente no que diz respeito ao nível de escolaridade exigido (Santos, 2006).

A Escola de Enfermagem Rachel Haddock Lobo foi criada em 1944, mas começou a funcionar efetivamente somente em 1948. Era vinculada à Secretaria Geral de Saúde a Assistência da Prefeitura do Distrito Federal, e foi integrada à Universidade do Estado da Guanabara (atual UERJ), em 1959. A EERHL pertencia à segunda geração de escolas de enfermeiras brasileiras criadas sob a influência norte-americana e foi um dos resultados, no campo da enfermagem, do acordo bilateral firmado entre o Brasil e os Estados Unidos da América do Norte em 1942, como parte da colaboração brasileira com o esforço das forças aliadas que combatiam na II Guerra Mundial. Como já vimos, na área da saúde pública, o acordo resultou na criação do Serviço Especial de Saúde Pública (SESP), uma agência paralela ao Ministério da Saúde e Educação com atuação restrita em áreas estratégicas de interesse militar e econômico, especificamente a região nordeste, região amazônica e no vale do Rio Doce. Uma das missões da EERHL era formar enfermeiras para atuar nas áreas do SESP.

A Tabela 1 apresenta a composição de cor conforme o que está registado nos prontuários das alunas das escolas de enfermeiras Carlos Chagas e Rachel Haddock Lobo. De início, observa-se que, além da classificação de quatros cores - branco, preta, amarela 
e parda -, conforme o estabelecido a partir do censo de 1940, nos registros escolares, $10 \%$ das alunas são declaradas de cor morena. Designamos alunas negras àquelas classificadas como de cor preta, parda e morena.

Tabela 1. Composição de Cor

\begin{tabular}{|l|l|l|l|l|l|}
\hline Escola/Cor & Preta & Parda & Morena & Branca & Total \\
\hline EECC (1936-1970) & $4(1 \%)$ & $35(7 \%)$ & $43(9 \%)$ & $397(83 \%)$ & $479(51 \%)$ \\
\hline EERHL (1951-1970) & $23(5 \%)$ & $63(14 \%)$ & $46(10 \%)$ & $323(71 \%)$ & $455(49 \%)$ \\
\hline Total & $27(3 \%)$ & $98(10,5 \%)$ & $89(9,5 \%)$ & $720(77 \%)$ & $934(100 \%)$ \\
\hline
\end{tabular}

O número total de alunas negras é praticamente igual nas duas escolas, mas a presença foi mais expressiva na escola Rachel Haddock Lobo, que, começou a funcionar efetivamente no começo no final da década de 1940. Levando em conta que a quantidade de enfermeiras diplomadas no período era considerada extremamente baixa, e que as candidatas negras sofriam discriminação racial, é relevante que 23\% (214 em números absolutos) das alunas que concluíram com sucesso o rigoroso curso de enfermagem fossem mulheres negras.

Se, como visto anteriormente, o grau de instrução escolar das candidatas era avaliado como um problema crônico enfrentado pelas escolas de enfermeiras, o resultado apresentado na Tabela 2 mostra que a maioria das alunas negras já tinha superado a barreira do ensino secundário (55\%), possuindo, portanto, o nível educacional desejável. Mas as alunas classificadas como de cor preta, além da presença discreta, também eram aquelas que detinham menor nível de escolaridade. Mesmo assim, a escolaridade não diferenciava negativamente as alunas negras.

\section{Tabela 2. Escolaridade}

\begin{tabular}{|l|l|l|l|l|}
\hline Escolaridade/Cor & Preta & Parda & Morena & Total \\
\hline Ginasial (8 anos de escolaridade) & $15(18 \%)$ & $32(38 \%)$ & $20(24 \%)$ & $67(45 \%)$ \\
\hline Secundário (12 anos de escolaridade) & $05(6 \%)$ & $41(50 \%)$ & $37(44 \%)$ & $83(55 \%)$ \\
\hline Total & $20(13 \%)$ & $73(48 \%)$ & $57(38 \%)$ & $150(100 \%)$ \\
\hline
\end{tabular}


A condição socioeconômica familiar das alunas negras foi avaliada a partir da posição ocupada pelo pai numa escala hierárquica de profissões e ocupações inspirada nos estudos sociológicos sobre o perfil do estudante universitário produzidos nos anos 1950 (Hutchinson, 1956; 1957). Os resultados apresentados na Tabela 3 indicam o predomínio de ocupações manuais (marceneiro, mecânico, chofer, lavrador, etc.) e também a presença frequente de funcionários públicos de escalão inferior (os barnabés) e de militares de baixa patente (cabos e sargentos). As ocupações do pai indicam que as famílias da maioria das alunas negras pertenciam ao universo das classes trabalhadoras urbanas típicas de uma sociedade ainda pouco industrializada. Como veremos na conclusão deste artigo, a posição social das alunas negras das escolas de enfermeiras está coerente com o indicado pelos estudos clássicos sobre a situação dos negros na sociedade brasileira nas décadas de 1950 e 1960 (Fernandes, 1978; PINTO, 1998).

\section{Tabela 3. Profissão ou Ocupação do Pai}

\begin{tabular}{|l|l|l|l|l|}
\hline Profissão ou Ocupação/Cor & Preta & Parda & Morena & Total \\
\hline Manual com/sem habilidades & 9 & 19 & 14 & $42(31 \%)$ \\
\hline Não manual padrão baixo e médio & 3 & 6 & 3 & $12(9 \%)$ \\
\hline $\begin{array}{l}\text { Profissões liberais (médico, advogado, } \\
\text { engenheiro) }\end{array}$ & 1 & 3 & 2 & $6(4,5 \%)$ \\
\hline Empresários/Comerciantes/Fazendeiros & - & 4 & 6 & $10(7 \%)$ \\
\hline Militares de baixa patente & 3 & 5 & 4 & $12(9 \%)$ \\
\hline Funcionário público baixo e médio escalão & 3 & 4 & 4 & $11(8 \%)$ \\
\hline Funcionário Público de alto escalão & - & 4 & 1 & $5(3,5 \%)$ \\
\hline $\begin{array}{l}\text { Aposentado } \\
\text { Sem informação }\end{array}$ & - & - & 2 & $2(1.5 \%)$ \\
\hline & 1 & 19 & 16 & $36(26,5 \%)$ \\
\hline & 19 & 64 & 53 & 136 \\
& & & & $(100 \%)$ \\
\hline
\end{tabular}

A análise da configuração familiar das alunas negras mostrou que elas pertenciam a famílias extensas. As alunas de cor preta eram as que possuíam o menor número médio de irmãos (2,5). Em contraste, as alunas pardas tinham, em média, o dobro de irmãos (4). O maior número médio de irmãos $(5,5)$ foi o observado entre as alunas morenas. Os dados sugerem configurações familiares que poderiam variar entre cinco membros (pretas) e oito membros (morenas). O tamanho das famílias é coerente com as ocupações das mães que confirmam o predomínio de atividades econômicas que podiam ser exercidas no ambiente doméstico em combinação com os papéis de esposa e/ou mãe. Os ofícios manuais tradicionais, como costureira e empregada doméstica, estão bem representados. 
Mas também se observa a presença de profissões modernas como professora primária, enfermeira ou funcionária pública, embora sejam pouco representativas. Ainda considerando o lugar ocupado pelo trabalho feminino no âmbito familiar, é muito sugestiva a diferença entre mães e filhas. As estudantes negras costumavam exercer atividades profissionais remuneradas antes de ingressarem nas escolas de enfermeiras. Além de professoras primárias, também constatamos a presença de auxiliares de enfermagem, visitadoras sanitárias, escriturárias, datilógrafas e operárias. Esse tipo de inserção no mundo do trabalho indica que, mesmo antes do ingresso nas escolas de enfermeiras, as estudantes negras já vinham realizando um movimento de mobilidade que as afastava das atividades tipicamente domésticas e manuais exercidas por suas mães.

\section{CONCLUSÃO}

O estudo realizado sobre as enfermeiras negras de duas escolas de enfermagem mostra como as desigualdades sociais e raciais são reproduzidas por políticas públicas. As mulheres negras constituíam, no período analisado, e ainda constituem, o grupo populacional mais atingido pela discriminação racial e pelas desigualdades sociais. Por outro lado, esse caso mostra também as estratégias e as vias por elas utilizadas escolarização e profissionalização - para escapar às barreiras sociais que as situavam em posições sociais subordinadas. Trata-se de um caso de mobilidade social e cultural agenciada de baixo para cima a partir da mobilização familiar, e das redes de sociabilidade nas quais estavam inseridas as enfermeiras negras.

Esse caso pode ser inscrito no movimento de mobilidade social verificado por Pinto (1998) e Fernandes (1978), no mesmo período, em suas pesquisas sobre as relações raciais no Distrito Federal e em São Paulo. Alguns aspectos e conclusões apresentados em suas obras contribuem para o entendimento sobre o caso aqui analisado, colocando-o em perspectiva ampliada.

Em primeiro lugar, chamam atenção para as ambiguidades e paradoxos do processo de incorporação da população de cor à vida urbana e ao trabalho livre. Como assinala Fernandes (1978, p. 117), as oportunidades de integração social à sociedade de massas eram restritas aos grupos que desfrutavam de posições de poder e de habilidades para conquistá-las como ponto de partida. Nesse sentido, essa ordem social era 
simultaneamente aberta e fechada; trazia consigo a pressão à integração, impelindo a população de cor a absorver as suas normas, valores e comportamentos, sem dar acesso, contudo, a todas as esferas da socialização e da participação de interesses econômicos, garantias sociais, e de bens culturais. Tratava-se, portanto, de uma pressão que não modificava a concentração da renda, do prestígio social e do poder. Além disso, embora o sistema social fosse aberto do ponto de vista da organização das relações raciais, a sociedade de classes não havia alterado os padrões de dominação racial herdados do passado que confere o monopólio do poder ao branco. Assim, a democratização das relações raciais constituía "um processo heterogêneo, lento e descontínuo" (Fernandes, 1978, p. 333). Qual então a natureza da mobilidade social alcançada por negros na sociedade de classes?

Para ambos, esse processo conduziu as populações negras à proletarização. Segundo Pinto (1998, p. 114), o "movimento de mobilidade conduziu negros da posição de escravo à de proletários. Foi essa a maior distância percorrida pela grande massa dos homens e mulheres de cor no Distrito Federal nos últimos setenta anos de mobilidade social". E, nesse sentido, de acordo com esse autor, o fato mais notável da mobilidade foi o afastamento em relação ao padrão tradicional de emprego quase exclusivo nas plantações tropicais, nas indústrias extrativas e no serviço doméstico, e a integração à vida urbana. Fernandes (1978, p. 160), por sua vez, percebia a absorção à ordem social como trabalhador assalariado como um fenômeno de mobilidade social de enorme importância sociológica, representando a superação da anomia de um grupo social colocado à margem da sociedade de classes.

Por outro lado, embora o processo de ascensão social consistisse numa via de mão dupla, isso é, operavam tanto as pressões da sociedade quanto o comportamento do negro, o verdadeiro motor da mobilidade residiu nas disposições dos indivíduos em ascender socialmente (Fernandes, 1978, p. 323). Isso porque os mecanismos sociais que atuavam para promover a integração social eram limitados e não tinham a finalidade de promover a igualdade econômica e social, mas sim ajustar o negro ao sistema de normas, interesses e valores da ordem social. Malgrado essas condições, o negro em ascensão social mobilizava diversos recursos para diferenciar e ampliar os seus papéis sociais. Assim, além da inserção na estrutura ocupacional da vida urbana, a educação foi um recurso 
utilizado pelo negro em ascensão, pois era percebida como um instrumento para conservar ou melhorar as posições sociais conquistadas.

\section{REFERÊNCIAS}

BIERNAT, Carolina; CERDÁ, Juan Manuel; RAMACCIOTTI, Karina Inés (Dir.) La salud pública y la enfermería em la Argentina. Buenos Aires: Universidad Nacional de Quilmes, 2105.

BROTTO, Renata Batista. $O$ sentido de servir: assistência e formação profissional de enfermeiras católicas no Brasil (1931-1961). 2014. Tese (Doutorado em Pós-Graduação em História das Ciências e da Saúde) - Fundação Oswaldo Cruz, Rio de Janeiro, 2014

BRUSCHINI, Maria Cristina Aranha. Mulher e Trabalho: engenheiras, enfermeiras e professoras. Cadernos de Pesquisa, São Paulo, n. 27, p. 5-16, 1978.

CAMPOS, André Luiz Vieira de. Cooperação internacional em saúde: o serviço especial de saúde pública e seu programa de enfermagem. Ciência \& Saúde Coletiva, v. 13, n. 3, p. 879-888, 2008.

CAMPOS, André Luiz Vieira. A Oficina Sanitária Pan-americana e a cooperação internacional na educação superior de enfermeiras no Brasil: 1942-1959. Revista Maracanan, v. 8, n. 8, p. $287-$ 307, 2012.

CASTRO-SANTOS, Luiz Antônio; FARIA, Lina. Saúde e História. São Paulo: Aderaldo \& Rotchschild, 2009.

CLARK, A. Kim. Gender, state and medicine in Highland Ecuador: modernizing women, modernizing the state, 1895-1950. Pittisburgh: University of Pittisburg Press, 2012.

ESCOLA ANNA NERY. Relatório narrativo da Divisão de Instrução de Enfermeiras, 1929.

CUETO, Marcos (ed.). Missionaries of science: the Rockefeller Foundation and Latin America. Bloomington: Indiana University Press, 1994

FERNANDES, Florestan. A integração do negro na sociedade de classes. São Paulo, Ática, 1978. v. 2.

FERREIRA, Márcia Cristina Lucas; SENA, Antônia Regina Messias Fernandes; BARREIRA, Ieda de Alencar. Minorias discriminadas e trabalho qualificado: o acesso de mulheres negras à enfermagem profissional nos anos 30. Revista de Enfermagem da Escola Anna Nery, v. 3, n. 1, p. 43-57, 1999.

FERREIRA-SANTOS, Célia Almeida. A enfermagem como profissão (estudo num hospitalescola). São Paulo: Pioneira, 1973.

HUTCHINSON, Bertran. Aspectos da educação universitária e status social em São Paulo. Educação e Ciências Sociais - Boletim do Centro Brasileiro de Pesquisas Educacionais, ano I, v. 1, n. 3, p. 91-107, dez. 1957.

HUTCHINSON, Bertram. Origem sócio-econômica dos estudantes universitárias de São Paulo. Educação e Ciências Sociais - Boletim do Centro Brasileiro de Estudos Educacionais, ano I, vol. 1, no 3, dezembro de 1956, p. 91-197 
LIGEIRO, Lorena Raeli; BAPTISTA, Suely de Souza. A exclusão de alunas de enfermagem da Escola Anna Nery (1930-1938). Revista de Enfermagem da Escola Anna Nery, v. 3, n. 1, p. 2442, 1999.

MACHADO, Maria Helena et al. Características gerais da enfermagem: perfil sócio demográfico. Enfermagem em Foco, v. 6, n. 1/4, p. 11-17, 2015.

MARINHO, Maria Gabriela S. M. C. Norte-americanos no Brasil: uma história da Fundação Rockefeller na Universidade de São Paulo (1934-1952). Campinas, São Paulo: Autores Associados, São Paulo: Universidade São Francisco, 2001

MENEZES, Simone dos Santos; BAPTISTA, Suely de Souza; BARREIRA, Ieda de Alencar. O perfil das (os) alunas (os) de enfermagem da Escola Anna Nery: décadas de 20, 30 e 90. Revista de. Enfermagem da Escola Anna Nery, v. 2, n. 1/2, p. 34-48, 1998.

MOREIRA, Martha Cristina Nunes. A Fundação Rockefeller e a construção da identidade profissional de enfermagem no Brasil na Primeira República. História, Ciências, Saúde Manguinhos, v. 3, p. 621-45, nov. 1998/fev. 1999.

NAKAMAE, Djair Daniel. Subsídios para a caracterização dos estudantes de enfermagem nos escolas do estado de São Paulo. Revista da Escola de Enfermagem da USP, v. 9, n. 2, p. 347-392, 1975

PERROT, Michelle. As mulheres e os silêncios da História. Bauru: Edusc, 2005.

PINTO, Luiz Costa. O negro no Rio de Janeiro. Relações de raças numa sociedade em mudança. Rio de Janeiro: Editora UFRJ, 1998.

RESENDE, Marina de Andrade. Interesse Geral - Enfermagem. Revista Brasileira de Enfermagem, ano XX. n. 2 e 3, p. 161-72, abr./jun. 1967.

RIBEIRO, Lourival. Anais de Enfermagem. V. III, n. 1, p. 1-13, mar. 1954. (separata)

SANTOS, Geralda Fortina dos. Escola de Enfermagem Carlos Chagas (1933-1950): a Deus pela humanidade-para o Brasil. Tese. (Doutorado em Enfermagem) - Universidade Federal de Minas Gerais, Belo Horizonte 2006.

SOUZA CAMPOS, Paulo Fernando de. Memorial de Maria Lurdes de Almeida: história e enfermagem no Brasil pós-1930. História, Ciências, Saúde - Manguinhos, v. 20, n. 2, p. 609-625, abr./jun. 2013.

SOUZA CAMPOS, Paulo Fernando de; OGUISSO, Taka. A Escola de Enfermagem da Universidade de São Paulo e a reconfiguração da identidade profissional da Enfermagem Brasileira. Revista Brasileira de Enfermagem, v. 61, n. 6, p. 892-898, nov./dez. 2008.

VESSURI, Hebe M. C. Enfermería de salud pública, modernizacion y cooperación internacional. El proyecto de la Escula Nacional de Enfermeras de Venezuela, 1936-1950. História, Ciência, Saúde-Manguinhos, v. VIII, n. 3, p. 507-39, set./dez. 2001.

Recebido em janeiro de 2019 Aprovado em março de 2019 